\title{
Betatrophin Levels were Increased in Pregnant Women with or without Gestational Diabetes Mellitus and Associated with Beta Cell Function
}

\section{Níveis de betatrofina aumentados em grávidas com ou sem diabetes mellitus gestacional e associados à função das células beta}

Yun Huang ${ }^{1}$ Chen Fang ${ }^{1}$ Zhimin Ma ${ }^{1}$ Heming Guo ${ }^{1}$ Ruihua Wang ${ }^{2}$ ji Hu${ }^{1}$

${ }^{1}$ Department of Endocrinology, The Second Affiliated Hospital of Soochow University, Suzhou, Jiangsu, China

2 Department of Gynecology and Obstetrics, The Second Affiliated Hospital of Soochow University, Suzhou, Jiangsu, China
Address for correspondence Ji Hu, MD, PhD, Department of Endocrinology, The Second Affiliated Hospital of Soochow University, 1055 Sanxiang Road, Suzhou, Jiangsu, China (e-mail: huji@suda.edu.cn).

Rev Bras Ginecol Obstet 2016;38:287-292.

\begin{abstract}
Keywords

- gestational diabetes mellitus

- pregnancy

- betatrophin

- $\beta$ cell function
\end{abstract}

Purpose betatrophin has been reported to boost $\beta$ cell expansion in insulin resistant states. Pregnancy is a well-recognized physiological state of insulin resistance. Betatrophin levels in pregnant women and their relationships with metabolic variables remain to be elucidated.

Methods A total of 49 pregnant women and 31 age-matched unpregnant women with normal glucose regulation (UP-NGR) were included. Among these subjects, according to results from $75 \mathrm{~g}$ oral glucose tolerance test (OGTT), 22 women were diagnosed as having gestational diabetes mellitus (GDM).

Results Our study found that pregnant women, regardless of their glucose regulation status, had remarkably higher triglycerides (TC), total cholesterol (TC), fasting insulin (FINS), homeostasis model assessment of insulin resistance (HOMA-IR) and homeostasis model assessment of $\beta$-cell function (HOMA- $\beta$ ). However, GDM patients had much lower HOMA- $\beta$ compared with those of pregnant women with normal glucose regulation (P-NGR). Participants of the P-NGR group had almost 4 times higher levels of betatrophin than those of the UP-NGR group. Although betatrophin levels were lower in the GDM group than those of the P-NGR group, the difference did not reach statistical significance. Spearman correlation analysis showed that betatrophin levels were positively and significantly associated with total cholesterol, triglycerides, highdensity lipoprotein cholesterol (HDL-c), FINS and HOMA- $\beta$. However, adjustments of TC, TG and HDL-c eliminated the association between HOMA- $\beta$ and betatrophin. Conclusions Pregnant women have significantly higher betatrophin levels in comparison to unpregnant women. Betatrophin levels are positively and significantly received December 21, 2015 accepted May 3, 2016
DOI http://dx.doi.org/ $10.1055 / \mathrm{s}-0036-1584566$. ISSN 0100-7203.
Copyright ( $\odot 2016$ by Thieme Publicações License terms Ltda, Rio de Janeiro, Brazil

() (1) $\odot \circledast$ 


\section{Resumo}

Palavras-chave

- diabetes mellitus gestacional

- gravidez

- betatrofina

- função das células $\beta$ associated with $\beta$ cell function and lipid levels. Furthermore, lipids may contribute to the association between betatrophin and $\beta$ cell function.

Introdução Betatrofina tem sido relacionada à expansão de células $\beta$ em estado de resistência à insulina. A gravidez é um conhecido estado fisiológico de resistência à insulina. Níveis de betatrofina em gestantes e sua relação com variáveis metabólicas ainda precisam ser esclarecidas.

Métodos Um total de 49 gestantes e 31 não gestantes de mesma idade com níveis normais de glicose (UP-NGR) foram incluídas. Dentre elas, de acordo com os resultados da curva glicêmica, base em $75 \mathrm{~g}, 22$ mulheres foram diagnosticadas com diabetes mellitus gestational (DMG).

Resultados Nosso estudo identificou que gestantes, independente de seus níveis de glicose, tiveram notáveis níveis elevados de triglicerídeos (TG), colesterol (TC), insulina em jejum (FINS), HOMA-IR e HOMA- $\beta$. Contudo, pacientes com DMG tiveram bem menos HOMA- $\beta$ se comparadas às gestantes com níveis normais de glicose (P-NGR). Participantes do grupo P-NGR tiveram níveis de betatrofina quase quarto vezes maiores ao das participantes do grupo UP-NGR. Embora os níveis de betatrofina sejam menores no grupo DMG do que no P-NGR, a diferença não obteve significância estatística. Análise da correlação de Spearman demonstrou que os níveis de betatrofina foram positiva e significativamente associados ao TC, TG, HDL-c (high-density lipoprotein cholesterol), FINS e HOMA- $\beta$. Contudo, ajustes em TC, TG e HDL-c eliminaram a associação entre HOMA- $\beta$ e betatrofina.

Conclusões Gestantes têm níveis de betatrofina significativamente maiores do que não gestantes. Níveis de betatrofina são positive e significativamente associados às células $\beta$ funcionais e níveis de lipídeos. Além disso, lipídeos podem contribuir na associação entre betatrofina e células $\beta$ funcionais.

\section{Introduction}

Betatrophin, (also known as angiopoietin-like protein 8 [ANGPTL8], lipasin, refeeding-induced fat and liver, and hepatocellular carcinoma-associated protein TD 26), a hormone primarily expressed in the liver and/or the adipose tissue, has been reported to promote pancreatic $\beta$ cell proliferation and expand $\beta$ cell mass in insulin resistant mice. ${ }^{1}$ Most studies conducted with type 2 diabetic patients found that betatrophin levels were significantly higher than those in healthy controls. ${ }^{2-6}$ However, results from clinical studies regarding betatrophin levels in insulin resistant populations were not consistent. ${ }^{4,7}$ Fenzl et $\mathrm{al}^{7}$ demonstrated that betatrophin levels did not differ between lean and morbidly obese participants. In contrast to their work, another study found that betatrophin levels were doubled in overweight subjects when compared with lean subjects. ${ }^{4}$

It has long been recognized that pregnancy is a physiological state of insulin resistance. ${ }^{8}$ Studies regarding betatrophin levels in pregnant women are limited. The study performed by Ebert et $\mathrm{al}^{9}$ indicated that betatrophin levels were increased in women with gestational diabetes mellitus (GDM) when compared with healthy pregnant controls, but they failed to detect any relationships between insulin resistance, $\beta$ cell function, and betatrophin levels. Therefore, the purpose of the present study is to investigate the betatrophin levels in pregnant women with normal glucose regulation (P-NGR), patients of GDM, unpregnant women with normal glucose regulation (UP-NGR), and explore their relationships with metabolic traits.

\section{Methods}

\section{Population}

A total of 49 pregnant women (age range: $22-43$ years) were recruited consecutively from the outpatient clinic of the department of endocrinology and obstetrics at the Second Affiliated Hospital to Soochow University in 2014. Thirty-one age-matched women (age range: 21-56 years) were recruited from the population that underwent a routine physical examination. Subjects with prior history of diabetes were not included in the present study. The study protocol was approved by the Institutional Review Board of the Second Affiliated Hospital to Soochow University. Informed consent was obtained from each participant. The diagnosis of GDM was defined according to the American Diabetes Association (ADA) criteria. ${ }^{10}$ Among these pregnant women, according to results from $75 \mathrm{~g}$ oral glucose tolerance test (OGTT), 22 were diagnosed as having GDM. 


\section{Clinical and Biochemical Measurements}

Three-point ( 0,1 and $2 \mathrm{~h}$ ) OGTT with a $75 \mathrm{~g}$ glucose load was performed in the pregnant women. Plasma glucose was measured using the glucose oxidase method on an autoanalyser (Cobas 8000, Roche, Basel, Switzerland). Serum total cholesterol (TC), triglycerides (TG), high-density lipoprotein cholesterol (HDL-c), and low-density lipoprotein cholesterol (LDL-c) were measured on an automated biochemical analyzer (Cobas 8000, Roche, Basel, Switzerland). Fasting serum insulin (FINS) levels were measured using an immunoradiometric assay (Roche Diagnostics GmbH, Germany). Serum betatrophin levels were measured using a commercially available enzyme-linked immunosorbent assay (ELISA) kit (Wuhan EIAab Science, Wuhan, China; catalogue No. E11644h).

\section{Definitions}

GDM was defined as meeting at least one of the following criteria: 1 ) fasting plasma glucose (FPG) $\geq 5.1 \mathrm{mmol} / \mathrm{L} ; 2) 1$ hour post-load plasma glucose $(1 \mathrm{~h}-\mathrm{PPG}) \geq 10.0 \mathrm{mmol} / \mathrm{L}$; and 3) 2 hour post-load plasma glucose ( $2 \mathrm{~h}-\mathrm{PPG}) \geq 8.5 \mathrm{mmol} / \mathrm{L}$. Normal glucose regulation was defined as without a history of diabetes, FPG $<6.1 \mathrm{mmol} / \mathrm{L}$ and glycosylated hemoglobin (HbA1c) $<6.0 \%$ or FPG $<6.1 \mathrm{mmol} / \mathrm{L}$ and $2 \mathrm{~h}-\mathrm{PPG}<7.8$ $\mathrm{mmol} / \mathrm{L}$. The indices of homeostasis model assessment of insulin resistance (HOMA-IR) and of homeostasis model assessment of $\beta$-cell function (HOMA- $\beta$ ) were calculated using the following formulas: HOMA-IR $=$ FINS $(\mathrm{mIU} / \mathrm{L}) \times$ FPG $(\mathrm{mmol} / \mathrm{L}) / 22.5$ and HOMA- $\beta=20 \times$ FINS $(\mathrm{mIU} / \mathrm{L}) / \mathrm{FPG}$ $(\mathrm{mmol} / \mathrm{L})-3.5$.

Body weight and height were measured in light clothes and without shoes to the nearest $0.1 \mathrm{~kg}$ and $0.5 \mathrm{~cm}$, in the
NGR group respectively. Body mass index (BMI) was calculated using the formula of weight $/$ height ${ }^{2}\left(\mathrm{~kg} / \mathrm{m}^{2}\right)$.

\section{Statistical Analysis}

Statistical analysis was performed using SAS 9.1 (SAS Institute, Cary, NC, USA). Variables were presented as mean \pm standard deviation (SD) or medians (interquartile ranges). Fasting serum triglyceride, FINS, HOMA-IR and HOMA- $\beta$ were transformed logarithmically due to non-normal distributions. Means of continuous variables were compared using the one-way analysis of variance (ANOVA).Spearman correlation and multivariable linear analyses were performed to evaluate the relationships between betatrophin levels and metabolic variables. The two-tailed test was used, and a $p<0.05$ was regarded as statistically significant.

\section{Results}

The present study population included three groups: UPNGR, P-NGR and women with GDM. As shown in - Table 1, age and LDL-c levels did not differ among the three groups; whereas pregnant women, regardless of their glucose regulation status, had remarkably higher TG, TC, FINS, HOMA-IR and HOMA- $\beta$ levels when compared with those in the UPNGR group (all $p<0.05$ ). HOMA-IR was not significantly different between the P-NGR and GDM groups; however, GDM patients had much lower HOMA- $\beta$ when compared with those of the P-NGR group $(p<0.05)$. As for betatrophin concentrations, subjects of the P-NGR group had almost 4 times more betatrophin than those of the UP-NGR group $(1,513.6$ [696.4-2,178.8] versus 283.3 [182.8-303.4] pg/mL,

Table 1 Clinical and metabolic characteristics of the study population

\begin{tabular}{|c|c|c|c|c|}
\hline & $\begin{array}{l}\text { UP-NGR } \\
\mathbf{n}=31\end{array}$ & $\begin{array}{l}\text { P-NGR } \\
\mathrm{n}=27\end{array}$ & $\begin{array}{l}\text { GDM } \\
\mathrm{n}=22\end{array}$ & $p$ \\
\hline Age (years) & $30.8 \pm 7.7$ & $29.3 \pm 4.2$ & $30.8 \pm 4.6$ & 0.58 \\
\hline BMI $\left(\mathrm{kg} / \mathrm{m}^{2}\right)$ & $21.0 \pm 3.2$ & - & - & - \\
\hline Duration of pregnancy (days) & - & $229 \pm 64$ & $218 \pm 56$ & 0.51 \\
\hline FPG (mmol/L) & $4.98 \pm 0.37$ & $4.43 \pm 0.39^{*}$ & $5.57 \pm 1.50^{*, * *}$ & 0.0001 \\
\hline 1h-PPG (mmol/L) & - & $7.62 \pm 1.69$ & $10.30 \pm 1.83$ & 0.0065 \\
\hline 2h-PPG (mmol/L) & $6.29 \pm 0.62$ & $6.62 \pm 1.39$ & $9.50 \pm 2.45^{*, * *}$ & $<0.0001$ \\
\hline FINS $(\mu \mathrm{IU} / \mathrm{mL})$ & $6.85(5.21-9.69)$ & $11.37(8.84-16.24)^{*}$ & $12.30(6.78-16.68)^{*}$ & 0.0002 \\
\hline HOMA-IR & $1.47(1.11-2.67)$ & $2.39(1.74-3.63)^{*}$ & $3.06(2.20-3.94)^{*}$ & 0.030 \\
\hline HOMA- $\beta$ (\%) & $98.0(77.3-133.7)$ & $306.7(163.8-477.6)^{*}$ & $153.1(90.2-282.0)^{*, * *}$ & $<0.0001$ \\
\hline $\mathrm{TC}(\mathrm{mmol} / \mathrm{L})$ & $4.81 \pm 0.91$ & $6.52 \pm 1.37^{*}$ & $5.69 \pm 1.30^{*, * *}$ & $<0.0001$ \\
\hline TG (mmol/L) & $0.73(0.56-1.00)$ & $2.82(1.95-3.33)^{*}$ & $3.04(2.30-3.54)^{*}$ & $<0.0001$ \\
\hline $\mathrm{HDL}-\mathrm{c}(\mathrm{mmol} / \mathrm{L})$ & $1.36 \pm 0.27$ & $1.93 \pm 0.45^{*}$ & $1.55 \pm 0.48^{* *}$ & $<0.0001$ \\
\hline $\mathrm{LDL}-\mathrm{c}(\mathrm{mmol} / \mathrm{L})$ & $2.74 \pm 0.82$ & $3.42 \pm 1.24^{*}$ & $2.93 \pm 0.85$ & 0.039 \\
\hline
\end{tabular}

Abbreviations: UP-NGR, unpregnant women with normal glucose regulation; P-NGR, pregnant women with normal glucose regulation; GDM, gestational diabetes mellitus; n, number; BMI, body mass index; FPG, fasting plasma glucose; PPG, post-load plasma glucose; FINS, fasting insulin; HOMA-IR, homeostasis model assessment of insulin resistance; HOMA- $\beta$, homeostasis model assessment of $\beta$-cell function; TC, total cholesterol; TG, triglycerides; HDL-c, high-density lipoprotein cholesterol; LDL-c, low-density lipoprotein cholesterol.

Notes: Data are means \pm standard deviation (SD) or medians (interquartile ranges).

Specific notes: ${ }^{*} \mathrm{p}<0.05$ as compared with UP-NGR; ${ }^{* *} \mathrm{p}<0.05$ as compared with P-NGR. 


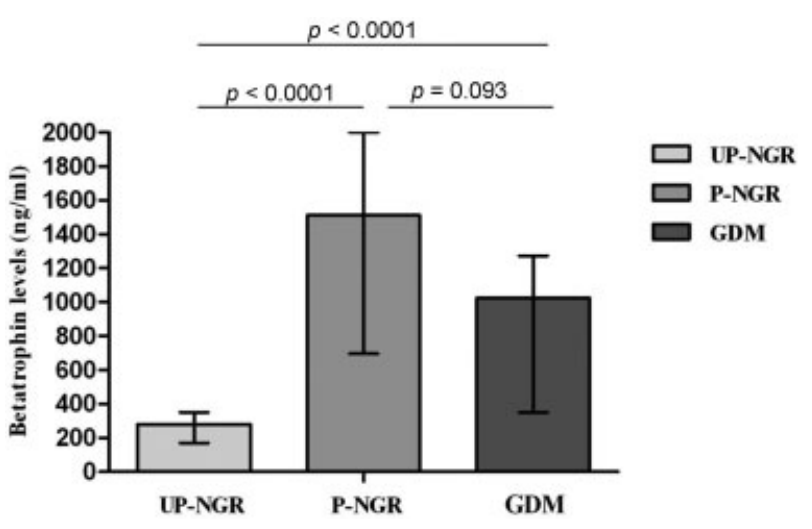

Fig. 1 Betatrophin levels in unpregnant women with normal glucose regulation, pregnant women with normal glucose regulation, and gestational diabetes mellitus patients.

$p<0.0001$, - Fig. 1.). Although betatrophin levels were much lower in the GDM group than in the P-NGR group, the difference did not reach statistical significance $(1,024.3$ [350.4-1,276.7] versus 1,513.6 [696.4-2,178.8] $\mathrm{pg} / \mathrm{mL}$, $p=0.093)$.

We then investigated the relationships between betatrophin and metabolic variables. Spearman correlation analysis revealed that betatrophin levels were positively and significantly associated with TC, TG, HDL-c, FINS, HOMA-IR and HOMA- $\beta$, but not with FPG and LDL-c (-Table 2). Further analysis regarding the effects of lipids on the relationships between betatrophin, FINS, HOMA-IR and HOMA- $\beta$ showed that the adjustment of TG, TC or HDL-c eliminated the association between betatrophin, FINS levels and HOMAIR. In contrast, although the magnitude of the association between betatrophin and HOMA- $\beta$ decreased, it still persisted. Multiple linear regression revealed that betatrophin levels associated to HOMA- $\beta$ in the model included age and duration of gestation as independent variables $(\beta \pm$ SEM: $0.45 \pm 0.14, p=0.0021)$. Nevertheless, after introducing TC, TG and HDL-c into the model, the association disappeared ( $\beta \pm$ SEM: $0.19 \pm 0.16, p=0.24)$, whereas TG remained significant ( $\beta \pm$ SEM: $0.39 \pm 0.18, p=0.03$ ).

\section{Discussion}

Our study showed that betatrophin levels were remarkably increased in pregnant women when compared with those of unpregnant women, and that they were positively associated with $\beta$ cell function and lipid levels.

Betatrophin was found to be involved in the compensatory $\beta$ cell proliferation in response to insulin resistance. ${ }^{1}$ Accumulating clinical studies investigated betatrophin levels in diabetic patients. Most studies conducted in type 2 diabetic patients found that betatrophin levels were increased and positively correlated with fasting glucose or FINS levels. $^{2-6}$ In contrast, circulating levels of betatrophin were significantly decreased or increased in obese participants. ${ }^{4,7}$ Another study found that betatrophin levels did not differ between lean and morbidly obese participants. ${ }^{11}$ Pregnancy is a well-recognized physiological state of insulin resistance, during which $\beta$ cell mass increases to adapt to the progressive insulin resistance that develops. Betatrophin messenger RNA (mRNA) in the liver increased by 20 -fold over the course of gestation in mice. ${ }^{1}$ However, results regarding betatrophin levels in pregnant women are limited. ${ }^{9,12}$ Our study demonstrated that the mean betatrophin levels in unpregnant women were $283.3 \mathrm{pg} /$

Table 2 Correlations between betatrophin, clinical and metabolic variables

\begin{tabular}{|c|c|c|c|c|c|c|c|c|}
\hline & r1 & p1 & r2 & p2 & r3 & p3 & r4 & p4 \\
\hline Age (years) & -0.0062 & 0.96 & & & & & & \\
\hline BMI $\left(\mathrm{kg} / \mathrm{m}^{2}\right)$ & 0.049 & 0.80 & & & & & & \\
\hline Duration of pregnancy (days) & 0.099 & 0.51 & & & & & & \\
\hline FPG (mmol/L) & -0.20 & 0.072 & -0.098 & 0.41 & -0.11 & 0.34 & -0.083 & 0.48 \\
\hline 2h-PPG (mmol/L) & 0.19 & 0.15 & 0.13 & 0.36 & 0.18 & 0.18 & 0.20 & 0.14 \\
\hline FINS $(\mu \mathrm{lU} / \mathrm{mL})$ & 0.30 & 0.0061 & 0.22 & 0.058 & 0.26 & 0.023 & 0.27 & 0.018 \\
\hline HOMA-IR & 0.24 & 0.034 & 0.17 & 0.15 & 0.21 & 0.069 & 0.23 & 0.053 \\
\hline HOMA- $\beta$ (\%) & 0.40 & 0.0003 & 0.25 & 0.035 & 0.29 & 0.013 & 0.28 & 0.016 \\
\hline $\mathrm{TC}(\mathrm{mmol} / \mathrm{L})$ & 0.32 & 0.0047 & - & - & & & & \\
\hline $\mathrm{TG}(\mathrm{mmol} / \mathrm{L})$ & 0.39 & 0.0004 & - & - & & & & \\
\hline HDL-c (mmol/L) & 0.36 & 0.0012 & - & - & & & & \\
\hline LDL-c (mmol/L) & 0.15 & 0.20 & - & - & & & & \\
\hline
\end{tabular}

Abbreviations: BMI, body mass index; FPG, fasting plasma glucose; PPG, post-load plasma glucose; FINS, fasting insulin; HOMA-IR, homeostasis model assessment of insulin resistance; HOMA- $\beta$, homeostasis model assessment of $\beta$-cell function; TC, total cholesterol; TG, triglycerides; HDL-c, high-density lipoprotein cholesterol; LDL-c, low-density lipoprotein cholesterol.

Notes: 1 1: unadjusted correlation coefficients; $p 1$ : unadjusted $p$ values; $r 2$ : correlation coefficients adjusted for triglycerides; $p 2$ : $p$ values adjusted for triglycerides; r3: correlation coefficients adjusted for total cholesterol; $p 3$ : $p$ values adjusted for total cholesterol; r4: correlation coefficients adjusted for HDL cholesterol; $p 4$ : $p$ values adjusted for HDL cholesterol. 
$\mathrm{mL}$, which was comparable to those measured by EIAab kits (Wuhan EIAab Science, Wuhan, China) from other studies. ${ }^{5,13}$ Compared with unpregnant women, pregnant women had 3-4 fold higher betatrophin levels; although the GDM group had lower levels of betatrophin, the difference did not reach statistical difference. In contrast, a recent study showed that betatrophin levels (measured by Phoenix kits - Phoenix Pharmaceuticals, Burlingame, CA, USA) were increased in women with GDM when compared with those of healthy pregnant controls. ${ }^{9}$ When interpreting the discrepancies in results measured by ELISA method, betatrophin proteolytic regulation should be taken into consideration. ${ }^{14}$ EIAab and Phoenix kits recognize the $\mathrm{N}$-terminus and C-terminus of betatrophin respectively. $\mathrm{N}$-terminal kit measures the full length protein, while C-terminal kit measures total betatrophin species, including both full-length protein and C-terminal fragment. Fu et al ${ }^{14}$ compared betatrophin levels in lean and obese participants with these two kits; however, results turned out to be contrary. Whether full-length or C-terminal fragment are functional in certain physiological or pathological conditions is unknown, as we noticed that most discrepancies were detected in insulin resistant populations, including obese and pregnant populations. Further studies focusing on the functions of full-length protein and C-terminal fragments are needed.

As expected, FINS, HOMA-IR and HOMA- $\beta$ were much higher in pregnant women in comparison to unpregnant women. In addition, in pregnant women, compared with normoglycemic pregnant women, GDM patients had significantly lower HOMA- $\beta$, which was consistent with the notion that GDM occurs when $\beta$ cell proliferation cannot compensate the increased demand of insulin. Yi et $\mathrm{al}^{1}$ indicated that increased expression of betatrophin could expand $\beta$ cell mass and improve glucose tolerance. ${ }^{1}$ Hence, a positive association between betatrophin and $\beta$ cell function can be speculated. In accordance with the speculation, correlation analysis also revealed that betatrophin levels were positively related to $\beta$ cell function.

Absence of ANGPTL8 (betatrophin) was found to profoundly disrupt TG metabolism and inhibit lipoprotein lipase. ${ }^{15,16}$ However, results from clinical studies were not consistent. Significant associations between TG, TC, HDL-c and betatrophin levels are found in the present study, which were in line with previous studies. ${ }^{7,15,16}$ In contrast, two recent studies failed to detect the association between betatrophin and lipid levels. ${ }^{9,12}$ Interestingly, we also observed that adjustments for TG, HDL and TC could eliminate the association between betatrophin and $\beta$ cell function, while TG remained independently related to betatrophin, which implied that lipids might contribute to the association. The finding is in line with the notion that betatrophin can affect TG metabolism but not glucose homeostasis. ${ }^{15,16}$

Some limitations of the present study are also noteworthy. The main one is cross-sectional and with a relatively small number of participants. A prospective study that includes pregnant women with normal glucose regulation in their second trimester is in progress. Secondly, the HbA1c level was not measured in every partic- ipant, so data regarding it were not presented. Thirdly, although HOMA- $\beta$ is a well-established surrogate index of $\beta$ cell function, more precise measurements, including the hyperinsulinemic euglycemic clamp technique, should be used in future studies.

In conclusion, we indicated that betatrophin levels were remarkably higher in pregnant women when compared with those in unpregnant women. Betatrophin levels were positively and significantly associated with $\beta$ cell function and lipid levels. Furthermore, the association between betatrophin and $\beta$ cell function might be largely dependent on lipid levels.

\section{Author Disclosure Statement}

None.

\section{Note}

Yun Huang and Chen Fang contributed equally to this work.

\section{Acknowledgments}

We are grateful to all the patients and volunteers who participated in this study. The work is supported by the grants from the National Natural Science Foundation of China (No. 81502865), the Natural Science Foundation of Jiangsu Province (No. SBK201340560), and the Natural Science Foundation for Colleges and Universities in Jiangsu Province (No. 13KJB320017).

\section{References}

1 Yi P, Park JS, Melton DA. Betatrophin: a hormone that controls pancreatic $\beta$ cell proliferation. Cell 2013;153(4):747-758

2 Chen X, Lu P, He W, et al. Circulating betatrophin levels are increased in patients with type 2 diabetes and associated with insulin resistance. J Clin Endocrinol Metab 2015;100(1): E96-E100

3 Espes D, Martinell M, Carlsson PO. Increased circulating betatrophin concentrations in patients with type 2 diabetes. Int $\mathrm{J}$ Endocrinol 2014;2014:323407

4 Fu Z, Berhane F, Fite A, Seyoum B, Abou-Samra AB, Zhang R. Elevated circulating lipasin/betatrophin in human type 2 diabetes and obesity. Sci Rep 2014;4:5013

$5 \mathrm{Hu} \mathrm{H}$, Sun W, Yu S, et al. Increased circulating levels of betatrophin in newly diagnosed type 2 diabetic patients. Diabetes Care 2014; 37(10):2718-2722

6 Xie X, Gao T, Yang M, et al. Associations of betatrophin levels with irisin in Chinese women with normal glucose tolerance. Diabetol Metab Syndr 2015;7:26

7 Fenzl A, Itariu BK, Kosi L, et al. Circulating betatrophin correlates with atherogenic lipid profiles but not with glucose and insulin levels in insulin-resistant individuals. Diabetologia 2014;57(6): 1204-1208

8 Buchanan TA, Metzger BE, Freinkel N, Bergman RN. Insulin sensitivity and B-cell responsiveness to glucose during late pregnancy in lean and moderately obese women with normal glucose tolerance or mild gestational diabetes. Am J Obstet Gynecol 1990; 162(4):1008-1014 
9 Ebert T, Kralisch S, Wurst U, et al. Betatrophin levels are increased in women with gestational diabetes mellitus compared to healthy pregnant controls. Eur J Endocrinol 2015;173(1):1-7

10 American Diabetes Association. Diagnosis and classification of diabetes mellitus. Diabetes Care 2013;36(Suppl 1):S67-S74

11 Gómez-Ambrosi J, Pascual E, Catalán V, et al. Circulating betatrophin concentrations are decreased in human obesity and type 2 diabetes. J Clin Endocrinol Metab 2014;99(10): E2004-E2009

12 Yilmaz H, Cakmak M, Darcin T, et al. Retraction: Elevated plasma levels of betatrophin in women with gestational diabetes mellitus. Exp Clin Endocrinol Diabetes 2015;123(6):376-381
13 Espes D, Lau J, Carlsson PO. Increased circulating levels of betatrophin in individuals with long-standing type 1 diabetes. Diabetologia 2014;57(1):50-53

14 Fu Z, Abou-Samra AB, Zhang R. An explanation for recent discrepancies in levels of human circulating betatrophin. Diabetologia 2014;57(10):2232-2234

15 Gusarova V, Alexa CA, Na E, et al. ANGPTL8/betatrophin does not control pancreatic beta cell expansion. Cell 2014;159(3):691-696

16 Wang Y, Quagliarini F, Gusarova V, et al. Mice lacking ANGPTL8 (Betatrophin) manifest disrupted triglyceride metabolism without impaired glucose homeostasis. Proc Natl Acad Sci U S A 2013; 110(40):16109-16114 